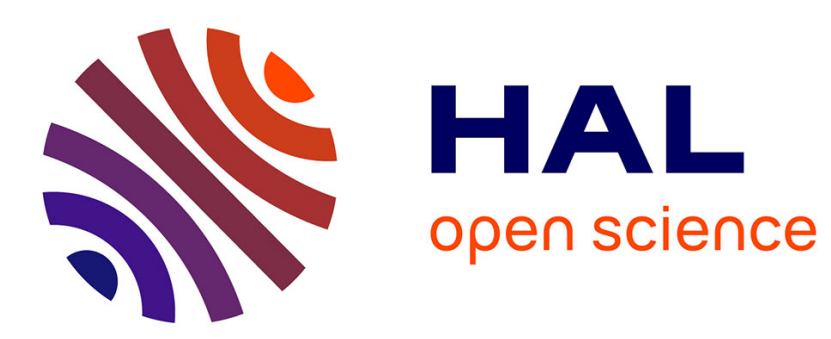

\title{
A $60 \mathrm{GHz}$ Off-Body Channel Implementation
}

Theodoros Mavridis, Luca Petrillo, Philippe de Doncker, Julien Sarrazin, David Lautru, Aziz Benlarbi-Delai

\section{To cite this version:}

Theodoros Mavridis, Luca Petrillo, Philippe de Doncker, Julien Sarrazin, David Lautru, et al.. A $60 \mathrm{GHz}$ Off-Body Channel Implementation. Conference IEEE 2013, Jul 2013, Orlando (FL), United States. hal-00802798

\section{HAL Id: hal-00802798 https://hal.sorbonne-universite.fr/hal-00802798}

Submitted on 11 Mar 2014

HAL is a multi-disciplinary open access archive for the deposit and dissemination of scientific research documents, whether they are published or not. The documents may come from teaching and research institutions in France or abroad, or from public or private research centers.
L'archive ouverte pluridisciplinaire HAL, est destinée au dépôt et à la diffusion de documents scientifiques de niveau recherche, publiés ou non, émanant des établissements d'enseignement et de recherche français ou étrangers, des laboratoires publics ou privés. 


\section{A $60 \mathrm{GHz}$ Off-Body Channel Implementation}

\author{
T. Mavridis, L. Petrillo and P. De Doncker \\ OPERA Dpt. - Wireless Communications Group, \\ Ecole Polytechnique de Bruxelles, \\ Brussels, Belgium. \\ tmavridi@ulb.ac.be
}

\author{
J. Sarrazin, D. Lautru and A. Benlarbi-Delaï \\ L2E, UR2, \\ UPMC Univ Paris 06, \\ Paris, France.
}

\begin{abstract}
In the field of smart environments, high data rate wireless wireless communication can be reached with the unlicensed $60 \mathrm{GHz}$ RF Band. In this spectrum, Body Area Networks channel modeling is required. In this paper, a $60 \mathrm{GHz}$ OffBody channel modeling is presented using a simplified and fast computation result of the scattering of plane waves by a human body at $60 \mathrm{GHz}$ and the IEEE 802.11ad indoor channel model.
\end{abstract}

\section{INTRODUCTION}

The fast development and progress in miniaturization and in Ultra Wide Band (UWB) components and wireless systems have driven the research to Body Area Network (BAN). Those developments require accurate and fast computation channel models to predict the received signal and allow to develop sophisticated communication techniques.

In this abstract, a 2D solution of the scattering of a plane wave by a dielectric cylinder modeling a human body will be presented. A 2D transition operator to convert the IEEE 802.11ad indoor channel model [1] into a Off-Body channel model is described.

In the full paper, experimental results and a $3 \mathrm{D}$ generalization of the results will be presented.

\section{SCATTERING Modeling}

The scattering of a plane wave on a cylinder has been widely studied by [2]. At $60 \mathrm{GHz}$, a formal development of this problem at $60 \mathrm{GHz}$ has been carried out to reach a fast computation solution, which is completely suitable to the IEEE 802.11ad indoor channel model.

The geometry is presented in Fig. 1 where $(\rho, \phi)$ are the polar coordinates where the total field is calculated, the cylinder has a radius $a$, a principal axis $\hat{z}$, a relative permittivity $\varepsilon_{r}$, a freespace permeability $\mu_{r}=1$ and $s_{r}$ is the travelled distance of the reflected wave and $\psi$ is the reflection angle. In the following, $k$ is the free-space wave number. The scattering model is split into two regions: the lit and shadow regions.

\section{A. Lit Region}

The total field for a TM incident plane wave $\mathbf{E}_{i}^{\mathrm{TM}}=$ $e^{i k r \cos (\phi)} \hat{z}$ is given by Geometrical Optics :

$$
\mathbf{E}_{\mathrm{tot}}^{\mathrm{TM}}=\left\{e^{i k \rho \cos (\phi)}-R \times e^{i k a \cos (\psi)} \sqrt{\frac{\rho_{r}}{\rho_{r}+s_{r}}} e^{-i k s_{r}}\right\} \hat{z}
$$

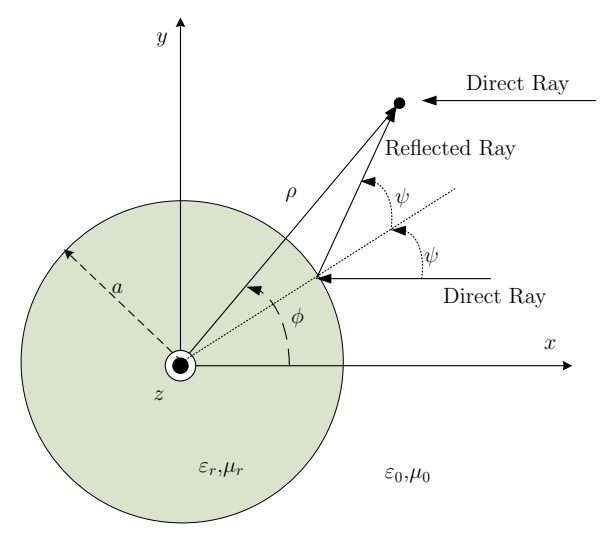

Fig. 1. Problem Geometry.

with the reflection coefficient is given by :

$$
R=\frac{\sin \psi-\sin \psi_{t}}{\sin \psi+\sin \psi_{t}}
$$

where the refracted angle is defined as $\psi_{t}=\arcsin \left(\sqrt{\varepsilon_{r}} \sin \psi\right)$ and $\rho_{r}=\cos \psi / 2$.

\section{B. Shadow Region}

The creeping wave in the shadow region is obtained by using Watson's transformation :

$$
E_{\text {Shadow }}^{\mathrm{TM}} \simeq 2 \pi j^{v+1} \frac{A^{\prime}(\tau)-q A(\tau)}{\tau W_{2}(\tau)-q W_{2}^{\prime}(\tau)} W_{2}(\tau-h) e^{-j v \phi}
$$

where $q=m \sqrt{\varepsilon_{r}}, m=(k a / 2)^{1 / 3}, v=k a+m \tau, h=$ $\frac{k}{m}(\rho-a)$ and $\tau$ is the first zero of:

$$
W_{2}^{\prime}(\tau)-q W_{2}(\tau)=0
$$

In those equations, $A(x)$ is the Airy function and $W_{2}(x)$ is the second kind Airy-Fock function defined in [3]. At $60 \mathrm{GHz}$, using the electric properties of the human skin, it results that $\tau=1.14201-1.9717 j$. In [4], it is shown that the model composed of (1) and (3) presented above fits with the exact solution given by the solution of the boundary problem [5]. An experimental validation has also been done and shows excellent agreement. 


\section{INDOOR OFF-BODY MODEL}

The purpose is to develop an indoor Off-Body channel model based on the scattering solution proposed above and the IEEE indoor channel model at $60 \mathrm{GHz}$.

\section{A. IEEE 802.11ad channel model}

The IEEE $802.11 \mathrm{ad} 60 \mathrm{GHz}$ indoor channel model generation is made of two steps [1]: the cluster simulation by ray tracing and the statistical definition of the intra-cluster paths. The output result of the model is a set of parameters :

$$
\alpha^{(i, k)}, \tau^{(i, k)}, \phi_{\mathrm{tx}}^{(i, k)} \text { and } \phi_{\mathrm{rx}}^{(i, k)}
$$

where the indexes $(i, k)$ denotes the $k^{\text {th }}$ ray of the $i^{\text {th }}$ cluster, $\alpha$ is the ray magnitude, $\tau$ is the time of arrival of the wave, $\phi_{\mathrm{tx}}, \phi_{\mathrm{rx}}$ are the azimuth angle at the transmitter and receiver. The elevation angle case is not presented in this abstract. The angles at the transmitter are not modified by the introduction of a cylinder at the receiver and will not be considered in the following. The angles defined in the following are defined by the normal of the cylinder at the receiver position.

\section{B. Transition Operator from indoor to Off-Body}

The aim is to define an operator $\mathcal{T}$ which allows to make the conversion of the (5) parameters from the IEEE indoor channel model to an Off-Body modeling. It can be shown that this operator $\mathcal{T}$ depends on three parameters $\left(a, \rho, \phi_{0}\right)$ where $a$ is the cylinder radius and $\left(\rho, \phi_{0}\right)$ are the coordinates of the receiver around the cylinder.

The transition operator is also depending on the relative position between the receiver and the direction of arrival of the considered wave. The transition operator can be split into two components: $\mathcal{T}^{\text {lit }}$ (when $\left|\phi_{0}-\phi_{\mathrm{rx}}^{(i, k)}\right|<\pi / 2$ ) and $\mathcal{T}^{\text {sha }}$ (when $\left|\phi_{0}-\phi_{\mathrm{rx}}^{(i, k)}\right| \geq \pi / 2$ ).

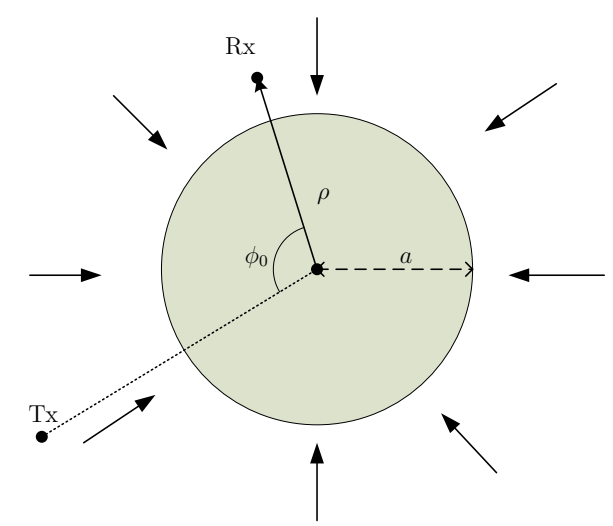

Fig. 2. Schema of the cylindrical body introduction. The arrows represent the indoor paths generated by the IEEE model.

\section{Shadow transition Operator}

The shadow transition operator is defined as the operator which converts an incident plane wave in a creeping wave denoted with $\mathrm{a}^{\prime}$.

$$
\left(\begin{array}{c}
\alpha^{(i, k)^{\prime}} \\
\tau^{(i, k)^{\prime}} \\
\phi_{\mathrm{rx}}^{(i, k)^{\prime}}
\end{array}\right)=\mathcal{T}_{\left(a, \rho, \phi_{0}\right)}^{\text {sha }}\left(\begin{array}{l}
\alpha^{(i, k)} \\
\tau^{(i, k)} \\
\phi_{\mathrm{rx}}^{(i, k)}
\end{array}\right)
$$

Using the creeping wave model (3), it can be shown that:

$$
\mathcal{T}_{\left(a, \rho, \phi_{0}\right)}^{\text {sha }}\left(\begin{array}{c}
\alpha^{(i, k)} \\
\tau^{(i, k)} \\
\phi_{\mathrm{rx}}^{(i, k)}
\end{array}\right)=\left(\begin{array}{c}
\alpha^{(i, k)} F(a, \rho) e^{-j v \phi} \\
\tau^{(i, k)}+\rho \frac{\left|\phi_{0}-\phi_{\mathrm{rx}}^{(i, k)}\right|-\pi / 2}{\pi^{c}}
\end{array}\right)
$$

where $c$ is the speed of light and

$$
F(a, \rho)=2 \pi j^{v+1} \frac{A^{\prime}(\tau)-q A(\tau)}{\tau W_{2}(\tau)-q W_{2}^{\prime}(\tau)} W_{2}(\tau-h) .
$$

\section{Lit transition Operator}

The transition operator in the lit region converts an incident plane wave into a direct wave denotes by ' and a reflected wave denotes by ".

$$
\mathcal{T}_{\left(a, \rho, \phi_{0}\right)}^{\mathrm{lit}}\left(\begin{array}{l}
\alpha^{(i, k)} \\
\tau^{(i, k)} \\
\phi_{\mathrm{rx}}^{(i, k)}
\end{array}\right)=\left(\begin{array}{c}
\alpha^{(i, k)^{\prime}} \\
\tau^{(i, k)^{\prime}} \\
\phi_{\mathrm{rx}}^{(i, k)^{\prime}}
\end{array}\right) \oplus\left(\begin{array}{c}
\alpha^{(i, k)^{\prime \prime}} \\
\tau^{(i, k)^{\prime \prime}} \\
\phi_{\mathrm{rx}}^{(i, k)^{\prime \prime}}
\end{array}\right)
$$

where the symbol $\oplus$ denotes the adding of a new wave. It can be shown that :

$$
\left(\begin{array}{c}
\alpha^{(i, k)^{\prime}} \\
\tau^{(i, k)^{\prime}} \\
\phi_{\mathrm{rx}}^{(i, k)^{\prime}}
\end{array}\right)=\left(\begin{array}{c}
\alpha^{(i, k)} \\
\tau^{(i, k)}-\frac{a \cos \left(\left|\phi_{0}-\phi_{\mathrm{rx}}^{(i, k)}\right|\right)}{\left|\phi_{0}-\phi_{\mathrm{rx}}^{(i, k)}\right|}
\end{array}\right)
$$

and

$$
\left(\begin{array}{c}
\alpha^{(i, k)^{\prime \prime}} \\
\tau^{(i, k)^{\prime \prime}} \\
\phi_{\mathrm{rx}}^{(i, k)^{\prime \prime}}
\end{array}\right)=\left(\begin{array}{c}
-R \times \alpha^{(i, k)} \sqrt{\frac{\rho_{r}}{\rho_{r}+s_{r}}} e^{-j k s_{r}} \\
\tau^{(i, k)}-\frac{a \cos \psi-s_{r}}{c} \\
\pi-\psi
\end{array}\right) .
$$

\section{CONCLUSION}

In the full paper, an Off-Body model taking account of the elevation angle will be presented for both TM and TE polarization modes which will allow to develop a complete Off-Body indoor channel modeling. Also experimental results for both TM and TE polarization will be shown.

\section{REFERENCES}

[1] A. Maltsev and al., Channel Models for $60 \mathrm{GHz}$ WLAN Systems, IEEE doc. 802.11-09/0334r8, 2010.

[2] P. H. Pathak and W. D. Burnside and R. J. Marhefka, A uniform GTD analysis of the diffraction of electromagnetic waves by a smooth convex surface, IEEE Transactions on Antennas and Propagation, 28, pp. 631-642, Sep. 1980.

[3] R. Paknis and N. Wang, High-Frequency Surface Field Excited by a Magnetic Line Source on an Impedance Cylinder, IEEE Transaction on Antennas and Propagation, 35, 3, pp. 293-298, 1987.

[4] T. Mavridis, L. Petrillo, J. Sarrazin, A. Benlarbi-Delaï and P. De Doncker, Analytical Creeping Waves Model At $60 \mathrm{GHz}$ for Off-Body Communications, EuCAP 2013, Accepted.

[5] C. A. Balanis, Advanced Engineering Electromagnetics, Wiley, 1989. 